\title{
Predictors of poor outcomes after significant chest trauma in multiply injured patients: a retrospective analysis from the German Trauma Registry (Trauma Register DGU ${ }^{\circledR}$ )
}

Stephan Huber ${ }^{1 *}$, Peter Biberthaler ${ }^{1}$, Patrick Delhey ${ }^{1}$, Heiko Trentzsch ${ }^{4}$, Hauke Winter ${ }^{3}$, Martijn van Griensven ${ }^{1}$, Rolf Lefering ${ }^{2}$, Stefan Huber-Wagner ${ }^{1}$ and Trauma Register DGU ${ }^{5}$

\begin{abstract}
Background: Blunt thoracic trauma is one of the critical injury mechanisms in multiply injured trauma victims. Although these patients present a plethora of potential structural damages to vital organs, it remains debated which injuries actually influence outcome and thereby should be addressed initially. Hence, the aim of this study was to identify the influence of critical structural damages on mortality.

Methods: All patients in the database of the TraumaRegister DGU® (TR-DGU) from 2002-2011 with AIS Chest $\geq 2$, blunt trauma, age of 16 or older and an ISS $\geq 16$ were analyzed.

Outcome parameters were in-hospital mortality as well as ventilation time in patients surviving the initial 14 days after trauma.

Results: 22613 Patients were included (mean ISS $30.5 \pm$ 12.6; 74.7\% male; Mean Age $46.1 \pm 197$ years; mortality 17.5\%; mean duration of ventilation $7.3 \pm 11.5$; mean ICU stay $11.7 \pm 14.1$ days).

Only a limited number of specific injuries had a significant impact on survival. Major thoracic vessel injuries (AIS $\geq 5$ ), bilateral lung contusion, bilateral flail chest, structural heart injury (AIS $\geq 3$ ) significantly influence mortality in study patients. Several extrathoracic factors (age, blood transfusion, systolic blood pressure and extrathoracic severe injuries) were also predictive of increased mortality.

Most injuries of the thoracic wall had no or only a moderate effect on the duration of ventilation. Injuries to the lung (laceration, contusion or pneumothoraces) had a moderate prolonging effect. Cardiac injuries and severe injuries to the thoracic vessels induced a substantially prolonged ventilation interval.

Conclusions: We demonstrate quantitatively the influence of specific structural damages of the chest on critical outcome parameters. While most injuries of the chest wall have no or only limited impact in the study collective, injuries to the lung overall show adverse outcome. Injuries to the heart or thoracic vessels have a devastating prognosis following blunt chest trauma.
\end{abstract}

Keywords: Polytrauma, Blunt chest trauma, Severly injured, Outcome, Chest wall injury, ISS, Mortality, Ventilation

\footnotetext{
*Correspondence: stephan.huber@mri.tum.de

'Department of Trauma Surgery, Klinikum rechts der Isar, Technical University

Munich - TUM, Ismaninger Str. 22, D-81675 Munich, Germany

Full list of author information is available at the end of the article
} 


\section{Background}

Blunt trauma to the chest and structural damages of vital organs inside the thoracic region have a substantial influence on morbidity and mortality for patients suffering from multiple injuries (polytrauma) Previous studies report about a mortality rate of up to $25 \%$ following severe thoracic trauma in polytrauma victims. In this respect, a recent report from the British Trauma Registry TARN has described a mortality of nearly $20 \%$ in 1164 patients sustaining blunt thoracic injury [1]. Recent publications obtained from data of the the German and British trauma registries described that blunt chest injuries are a serious medical and economic challenge in western industrial nations and that severe thoracic trauma can induce high mortality and prolonged ventilation periods.

However, due to the broad variance of influence of thoracic structures on prognosis, blunt thoracic trauma is a very heterogeneous entity. A number of scoring systems have been developed to evaluate the prognosis of patients following blunt thoracic trauma such as the Thoracic Trauma Score (TTS), Pulmonary Contusion Score (PCS) or the Wagner Score, which were calculated as independent indicators of prognosis considering mortality and morbidity following blunt thoracic trauma [2]. Moreover, age of 65 years or above has been described as a major predictor of mortality and required ventilation $[3,4]$.

Multiple injuries to the chest and its organs are found in the majority of patients after blunt thoracic trauma $[1,5]$.

However, for chest wall injuries such as rib fractures or flail chest, existing data remain controversial as to their prognostic impact, which is not consistent in prior investigations $[3,4,6]$. Some injuries such as major cardiac injury or injury of thoracic vessels are clearly immediately life-threatening injuries [7]. On the other hand, the impact of lung parenchymal injuries or pulmonary contusions also remains controversial in previous studies $[8,9]$.

Since the widespread introduction of CT scans to initial diagnostics in polytrauma patients, the sensitivity has increased and more injuries are identified immediately upon admission of patients after thoracic trauma [10]. Many structural damages are visualized in multi-slice computerized tomography (MSCT) as compared to conventional radiography in this collective [11].

Although it has been demonstrated that structural damages of intrathoracic organs may reduce the prognosis so far no clear quantitative ranking of the influence of specific injuries on morbidity and mortality were calculated. Hence, the aim of this study was to calculate the influence of specific anatomic structural damages in patients suffering from polytrauma with concomittant thoracic trauma on relevant outcome parameters. This study was performed on a large data collective of multiply injured patients, the TraumaRegister DGU ${ }^{\circ}$ (TR-DGU).

\section{Methods}

\section{Study design}

This study was designed as a retrospective cohort study on data of trauma victims recorded in the national trauma registry of Germany (TraumaRegister DGU ${ }^{\circ}$ ). The observation period was from 2002 until 2011. Further details on the TraumaRegister can be found under the paragraph data collection.

To clarify the methodology of the study, we have divided methodology and results into three parts:

Part I results consist of patients demographic data as well as the influence of various demographic details on survival.

Part II results consist of a logistic regression analysis and forward selection of significant dependent variables to show the influence of various injuries on patient survival.

Part III results show the influence of various injuries on ventilator days in patients surviving the first 14 days after thoracic trauma as analyzed by multiple linear regression and stepwise forward selection. The deviation from the mean duration of ventilation in the sudy population is indicated as prolonged ventilation.

\section{Inclusion criteria in the study}

Inclusion criteria were blunt trauma, ISS $\geq 16$, sufficient data information to calculate the Revised Injury Severity Classification (RISC) score, AIS Chest of $\geq 2$ and an age of 16 years or older at the day of injury.

Diagnoses following trauma are entered in a web based interface and stored in the form of the revised AIS score (2005 version). Diagnoses were identified in the data set by searching for the respective AIS code.

There was no specific funding for this study, It was completely financed by the Technical University Munich.

\section{Data collection}

The data source for our study was the the TraumaRegister $\mathrm{DGU}^{\bullet}$, which was started in 1993. It comprises data of major trauma patients of 266 trauma centers mostly from German-speaking countries (Germany, Austria, and Switzerland, but also The Netherlands, Belgium, and Slovenia; as in 2009). It is a prospective, multicenter, standardized and anonymized database. Every trauma patient admitted to one of the participating trauma hospitals with an injury severity score (ISS) $\geq 16$ or ICU treatment is documented in the registry. Data is continuously entered into a web-based data server that is hosted by the German Trauma Society and its Academy for Trauma Surgery (AUC). Irreversible data anonymity is guaranteed both for the individual patients and the participating hospitals. The registry comprises epidemiologic, physiologic, 
laboratory, diagnostic, operative, interventional and intensive care medical data as well as scoring and outcome data [12].

We analyzed patients from the period from 01/01/ $2002-12 / 31 / 2011$ for reasons of data homogenicity.

\section{Statistical analysis}

All statistical analyses were performed using SPSS version 21. Patients entered into the registry who suffered an accident between 2002 and 2011 were analyzed.

After identification of the enclosure variable "thoracic trauma", the primary end-point was set as "in-house hospital mortality" to divide the collective in two dichotome collectives. Then, logistic regression models and stepwise forward selection were calculated to identify independent and dependent variables which influence the primary outcome variable. The influence of various factors on the target-variable duration of ventilation was analyzed by using multiple linear regression and stepwise forward selection as was described before [13] (inclusion $\mathrm{p}<0.01$ ).

For the demographic section, we have subdivided the study collective in different subgroups and have made a dichotome analysis of mortality of the collectives respective of their division (age, gender).

\section{Results}

\section{Part I: Patient demographics}

Within the observation period from 2002-2011, more than 93000 patients were recorded in the trauma registry of the TraumaRegister DGU ${ }^{\circ}$ (TR-DGU). From these, 22613 patients fulfilled the primary study variable "thoracic trauma" and were enrolled into further statistical analysis.

The mean age was 46.1 years and $74.7 \%$ of the patients were male. Detailed information concerning demographics is depicted in Table 1.

\section{Mechanism of injury}

The most frequent mechanism of injury in the overall study population was Road Traffic Accidents (RTAs). Overall, RTAs made up for $56.0 \%$ of mechanisms of injury with car crashes being the most frequent cause

Table 1 Demographics of study patients

\begin{tabular}{lll}
\hline & Mean & Standard deviation \\
\hline Age & 46.1 & 19.7 \\
ISS & 30.6 & 12.6 \\
Days of ventilation & 7.3 & 11.5 \\
Days admission to ICU & 11.7 & 14.1 \\
Days admission to hospital & 25.3 & 25.0 \\
Mean RR on admission & 116.7 & 34.8 \\
\hline
\end{tabular}

The table shows the demographic properties of the overall study population that met the inclusion criteria. among RTAs (36.4\%) followed by motorcycle crashes (16.8\%) and injured pedestrians (7.4\%). Falls made up for most of the remaining injuries (overall 27.4\%; see Table 2).

\section{Mortality after blunt thoracic trauma is influenced by age} and gender

The outcome following Blunt Thoracic Trauma has been analyzed by forming 4 groups of patients. Patients in groups aged $<55$ years (mortality 13.5\%) and between 55-64 years (15.7\%) are less likely to die following blunt chest trauma than the average patient (17.5\%). Patients aged $65-74$ years $(24.0 \%$ mortality) and over 75 years of age $(40.0 \%)$ are severely at risk (see Table 3 ).

Male patients not only sustained a severe thoracic injury more often. Also, they suffered a lower mortality (16.5\%) following blunt chest trauma than female patients (20.5\%; see Table 4).

\section{Influence of extrathoracic injuries on mortality}

The prognostic impact of extrathoracic injuries has been quantified in the most relevant AIS categories head, abdomen and extremity injuries Less severe injuries have no negative impact on mortality as compared to patients without injuries of the respective body regions in all groups. Injuries with AIS of $\leq 3$ in all groups showed better rather than adverse mortality. AIS scores of 4 or greater in all extrathoracic regions however are correlated with mortality in a linear fashion (see Table 5).

\section{Prevalence of thoracic injuries in the study group}

The prevalence of common thoracic injuries was quantified in the study population and the results are depicted in Table 6.

Simple rib fractures of one or more ribs were a common injury and are found in roughly a third of patients, while flail chest is less common; sternal fractures are encountered only in about every tenth patient.

Lung contusion is common in patients with blunt thoracic injuries and found in about half of the patients; lung parenchymal injury on the other hand is comparatively

Table 2 Mechanisms of injury in the study population

\begin{tabular}{ll}
\hline & Percent of study population \\
\hline Car passenger & 35.6 \\
Motorcyclist & 16.5 \\
Cyclist & 6.5 \\
Pedestrian & 7.3 \\
Fall $>\mathbf{3 ~} \mathbf{m}$ & 19.6 \\
Fall $<\mathbf{3 ~ m}$ & 7.3 \\
Others & 5.0 \\
Total & $\mathbf{1 0 0}$ \\
\hline
\end{tabular}

The table shows the relative proportions of the mechanisms of injury in the study population as documented in the Traumaregister. 
Table 3 Outcome following blunt chest trauma depending on age the table shows mortality dependent on age in different subgroups of the overall study population

\begin{tabular}{llll}
\hline Age & Survived & Died & Total \\
\hline$<\mathbf{5 5}$ years & 13055 & 2034 & 15089 \\
& $86.5 \%$ & $13.5 \%$ & $100 \%$ \\
$\mathbf{5 5 - 6 4}$ years & 2301 & 429 & 2730 \\
& $84.3 \%$ & $15.7 \%$ & $100 \%$ \\
$\mathbf{6 5 - 7 4}$ years & 1953 & 616 & 2569 \\
& $76.0 \%$ & $24.0 \%$ & $100 \%$ \\
$\mathbf{7 7 5}$ years & 1336 & 889 & 2225 \\
& $60.0 \%$ & $40.0 \%$ & $100 \%$ \\
Total & 18645 & 3968 & 22613 \\
& $82.5 \%$ & $17.5 \%$ & $100 \%$ \\
\hline
\end{tabular}

rare and found only in one in ten patients. The occurrence of hemothorax was common as were pneumothoraces. Injuries to thoracic vessels or cardiac injuries are infrequent.

\section{Part II: Influence of thoracic injuries on survial}

We next sought to identify which factors actually determine survival in severely injured patients after blunt thoracic trauma. Therefore, we performed univariate analysis with forward selection to identify which diagnoses actually pose a severe threat to survival in these severely injured patients (Table 7).

The only thoracic wall injury that was significantly associated with elevated mortality was bilateral flail chest, which had a moderately elevated Odds Ratio. None of the other chest wall injuries was significantly predictive of increased mortality.

Neither hemothoraces nor pneumothoraces themselves were associated with adverse prognoses regarding mortality, suggesting that even tension pneumothorax is usually recognized and treated successfully. Lung injuries such as contusions or lacerations were only predictive if major or bilateral. Injuries to thoracic vessels or heart injuries were severe injuries with drastically impaired chances of survival.

Table 4 Outcome following blunt chest trauma depending on gender the table shows mortality dependent on gender in the two subgroups of the overall study population

\begin{tabular}{llll}
\hline & Survived & Died & Total \\
\hline Female & 4525 & 1166 & 5691 \\
& $79.5 \%$ & $20.5 \%$ & $100 \%$ \\
Male & 13998 & 2773 & 16771 \\
& $83.5 \%$ & $16.5 \%$ & $100 \%$ \\
\multirow{2}{*}{ Total } & 18523 & 3969 & 22462 \\
& $82.5 \%$ & $17.5 \%$ & $100 \%$ \\
\hline
\end{tabular}

Part III: Impact of extrathoracic factors additional to thoracic injuries on ventilator days

In order to analyze the influence of various factors on the duration of ventilation following blunt chest trauma, ventilation days were analyzed. Only patients who survived the first 14 days following injury were investigated using multivariate linear regression analysis (as demonstrated in Table 8). Our analysis identified a plethora of injuries as well as extrathoracic factors that prolong ventilation.

Extrathoracic factors known to generally cause increased mortality also prolong ventilation in our study (age over 65 years, blood transfusion, shock, extrathoracic severe injury).

Some injuries to the thoracic wall that do not have a significant effect on mortality such as unilateral flail chest are independent predicting factors of prolonged ventilation following blunt chest trauma in our study collective, but only cause moderate prolongation. Nearly every type of injury to the lung parenchyma (lung contusions as well as lung laceration) statistically prolongs ventilation with a linear correlation of injury severity to the expected prolongation.

While the presence of a hemo- or pneumothorax in a patient following severe chest trauma is not predictive of mortality, hemo- and severe pneumothoraces are significant predictors of prolonged ventilation, albeit to a moderate degree.

Major thoracic vessel- and cardiac injuries not only pose highly lethal injuries in our analysis, but also drastically prolong ventilation in survivors.

\section{Discussion}

Based on the analysis of a collective of 22613 patients with severe chest injury from the database of the TraumaRegister $\mathrm{DGU}^{\oplus}$, we demonstrate for the first time the influence of specific structural damages of thoracic organs on the mortality of patients regarding their risk of mortality. Furthermore, we demonstrated the quantitative effect of specific injuries on the duration of ventilation in survivors using multiple linear regression and stepwise forward selection.

Blunt thoracic trauma is a common form of injury in severely injured patients and a frequent cause of mortality and morbidity in severely injured patients $[1,2,5,14]$.

A number of previous studies have addressed the prognosis of patients with blunt thoracic trauma. Pape et al. devised a scoring system (the Thoracic Trauma Score TTS) from observations in a series of 1495 trauma patients with blunt chest injury with the aim of having early guidance for clinical decision-making. They found that injuries to the parenchymal organs showed greater correlation to mortality and prolonged ventilation than chest wall injuries [4]. This finding is so far consistent 
Table 5 Influence of extrathoracic injuries on mortality following blunt chest trauma

\begin{tabular}{|c|c|c|c|c|c|c|c|c|c|}
\hline \multirow[b]{2}{*}{ AIS } & \multicolumn{3}{|l|}{ Head } & \multicolumn{3}{|l|}{ Abdomen } & \multicolumn{3}{|l|}{ Extremity } \\
\hline & Survived & Died & Total & Survived & Died & Total & Survived & Died & Total \\
\hline \multirow[t]{2}{*}{0} & 7295 & 1034 & 8239 & 10558 & 2284 & 12842 & 4771 & 1306 & 6077 \\
\hline & $87.6 \%$ & $12.4 \%$ & $100 \%$ & $82.2 \%$ & $17.8 \%$ & $100 \%$ & $78.5 \%$ & $21.5 \%$ & $100 \%$ \\
\hline \multirow[t]{2}{*}{1} & 1331 & 64 & 1395 & 54 & 3 & 57 & 352 & 38 & 390 \\
\hline & $95.4 \%$ & $4.6 \%$ & $100 \%$ & $94.7 \%$ & $5.3 \%$ & $100 \%$ & $90.3 \%$ & $9.7 \%$ & $100 \%$ \\
\hline \multirow[t]{2}{*}{2} & 2509 & 196 & 4027 & 4123 & 497 & 4620 & 6359 & 949 & 7308 \\
\hline & $92.8 \%$ & $7.2 \%$ & $100 \%$ & $89.2 \%$ & $10.8 \%$ & $100 \%$ & $87.0 \%$ & $13.0 \%$ & $100 \%$ \\
\hline \multirow[t]{2}{*}{3} & 3521 & 506 & 4027 & 2208 & 427 & 2635 & 5164 & 872 & 6036 \\
\hline & $87.4 \%$ & $12.6 \%$ & $100 \%$ & $83.8 \%$ & $16.2 \%$ & $100 \%$ & $85.6 \%$ & $14.4 \%$ & $100 \%$ \\
\hline \multirow[t]{2}{*}{4} & 2504 & 519 & 3012 & 1168 & 396 & 1564 & 1707 & 535 & 2242 \\
\hline & $82.8 \%$ & $17.2 \%$ & $100 \%$ & $74.7 \%$ & $25.3 \%$ & $100 \%$ & $76.1 \%$ & $23.9 \%$ & $100 \%$ \\
\hline \multirow[t]{2}{*}{5} & 1441 & 1437 & 2878 & 532 & 355 & 887 & 292 & 268 & 560 \\
\hline & $50.1 \%$ & $49.9 \%$ & $100 \%$ & $60.0 \%$ & $40.0 \%$ & $100 \%$ & $52.1 \%$ & $47.9 \%$ & $100 \%$ \\
\hline \multirow[t]{2}{*}{6} & 44 & 212 & 256 & 2 & 6 & 8 & n.a. & n.a. & n.a. \\
\hline & $17.2 \%$ & $82.8 \%$ & $100 \%$ & $25.0 \%$ & $75.0 \%$ & $100 \%$ & & & \\
\hline
\end{tabular}

with the data obtained in our study, which also indicates a significantly adverse prognosis after blunt thoracic trauma if the parenchymal organs are affected.

Many reports have addressed the consequences of single injuries on the prognosis following blunt chest trauma. The mortality of rib fractures following chest trauma has already been extensively studied with controversial findings. However, there is a consensus that rib fractures show increased mortality in the elderly $[15,16]$ and that a higher number of fractured ribs correlates with adverse outcome $[17,18]$.

Our study results show that older patients have drastically inferior outcome following blunt chest trauma with rib fractures and are well in line with previous findings. However, due to the nature of the AIS classification, which is used to enter and analyze diagnoses in the TraumaRegister $\mathrm{DGU}^{\circ}$, all rib fractures of three or more ribs are

Table 6 Frequency of injuries (\% are rounded up if above 1\%)

\begin{tabular}{ll}
\hline Injury & $\mathbf{n =}(\%$ of patients) \\
\hline Lung contusion & $10864(48 \%)$ \\
Pneumothorax & $8878(39 \%)$ \\
Rib fractures & $7794(35 \%)$ \\
Hemothorax & $6223(28 \%)$ \\
Flail chest & $3681(16 \%)$ \\
Lung laceration & $2644(12 \%)$ \\
Sternal fracture & $1947(8 \%)$ \\
Thoracic vessel injuries & $633(3 \%)$ \\
Cardiac injury & $171(0.8 \%)$ \\
\hline
\end{tabular}

The relative frequencies of the respective injuries have been investigated in the overall study population and the result is shown in Table 6. analyzed in the same group. However, we found no effect of rib fractures on survival or ventilation. Nevertheless, the overall effect of rib fractures on mortality remains controversial following our study, given that a recent meta-analysis identified three or more rib fractures as a predictor of mortality while another retrospective large study has not found rib fractures to be an independent prognostic factor in 35416 patients [14,19].

Only few reports have addressed the prognosis of sternal fractures; without additional injuries they are described to have a rather benign prognosis $[20,21]$. Consistent with these findings, we did not identify the diagnosis of a sternal fracture to be an independent predictor of morbidity or mortality.

Flail chest injuries have more increased mortlity than other chest wall injuries in our study. While only bilateral flail chest is associated with increased mortality, all forms of flail chest were found to be predictive of prolonged ventilation. Bilateral flail chest has previously been found to be a severely threatening condition compared to unilateral flail chest [22]. The rather benign prognosis of unilateral flail chest has been confirmed by a study of 262 cases where an isolated unilateral flail chest was associated with a mortality of about $6 \%$ [23].

Besides the mortality of chest wall injuries, the outcomes of the diverse intrathoracic injuries have been previously addressed in a number of studies. Pulmonary contusion seems to contribute to the likelihood and length of mechanical ventilation $[8,9]$. Especially the notion that the likelihood and length of ventilation correlate with the extent of lung contusion matches the findings of our study. In our study, limited lung contusion does not have an effect but extensive lung contusion is associated 
Table 7 Influence of extrathoracic factors and thoracic diagnoses on survival (factors with significantly adverse prognosis are written in bold letters)

\begin{tabular}{|c|c|c|c|c|c|}
\hline & \multirow{2}{*}{$\begin{array}{l}\text { Regression } \\
\text { coefficient B }\end{array}$} & \multirow{2}{*}{$\begin{array}{l}\text { Significance } \\
p=\end{array}$} & \multirow{2}{*}{$\begin{array}{l}\operatorname{Exp}(B)= \\
\text { odds ratio }\end{array}$} & \multicolumn{2}{|c|}{$95 \% \mathrm{Cl}$ for OR } \\
\hline & & & & Upper & Lower \\
\hline Thoracic vessel injuries & & .000 & & & \\
\hline Vessel injuries AIS 2 & .554 & .310 & 1.740 & .597 & 5.071 \\
\hline Vessel injuries AIS 3 & .913 & .000 & 2.492 & 1.522 & 4.081 \\
\hline Vessel injuries AIS 4 & -.020 & .927 & .980 & .634 & 1.513 \\
\hline Vessel injuries AIS 5 & 1.683 & .000 & 5.382 & 3.669 & 7.894 \\
\hline Vessel injuries AIS 6 & 2.864 & .000 & 17.531 & 7.688 & 39.976 \\
\hline Lung contusions & & .000 & & & \\
\hline Unilateral minor (AIS 2) & -.577 & .000 & .562 & .474 & .665 \\
\hline Unilateral major (AIS 3) & -.264 & .000 & .768 & .682 & .865 \\
\hline Bilateral (AIS 4) & .374 & .000 & 1.454 & 1.226 & 1.723 \\
\hline Lung lacerations & & .000 & & & \\
\hline Unilateral minor (AIS 3) & -.280 & .015 & .756 & .603 & .948 \\
\hline Unilateral major or bilateral minor (AIS 4) &,- 103 & 290 &, 902 &, 745 & 1,092 \\
\hline Bilateral major (AIS 5) & 1,114 &, 000 & 3,047 & 2,061 & 4,505 \\
\hline Rib fractures & &, 000 & & & \\
\hline One rib (AIS 1) &,- 018 & 895 &, 983 & ,758 & 1,273 \\
\hline Two ribs (AIS 2) &,- 558 &, 000 &, 572 &, 467 & ,702 \\
\hline Three or more (AIS 3) &,- 338 &, 000 &, 713 &, 630 &, 808 \\
\hline Flail chest & &, 000 & & & \\
\hline Unilateral minor (AIS 3) &,- 089 &, 374 &, 914 &, 751 & 1,114 \\
\hline Unilateral minor (AIS 3) &,- 091 &, 408 &, 913 & ,737 & 1,132 \\
\hline Bilateral (AIS 5) &, 530 &, 000 & 1,698 & 1,401 & 2,059 \\
\hline Patient age & &, 000 & & & \\
\hline Age 55-64 & ,424 &, 000 & 1,527 & 1,313 & 1,777 \\
\hline Age $65-74$ & 970 &, 000 & 2,638 & 2,298 & 3,028 \\
\hline Age $75+$ & 1,940 &, 000 & 6,957 & 6,100 & 7,934 \\
\hline Pneumothorax/Hemopneumothorax & &, 000 & & & \\
\hline Minor Pneumothorax/NFS (AIS 2) &,- 332 &, 000 &, 718 &, 596 &, 864 \\
\hline Minor Hemopneumothorax (AIS 3) &,- 309 &, 000 &, 734 &, 626 &, 861 \\
\hline Major Hemothorax or Pneumothorax (AIS 4) &,- 050 &, 475 &, 952 &, 830 & 1,090 \\
\hline Tension (AIS 5) &, 136 & 187 & 1,145 & ,936 & 1,401 \\
\hline Blood transfusion & & ,000 & & & \\
\hline 1-9 Units &, 598 &, 000 & 1,819 & 1,628 & 2,033 \\
\hline $10+$ Units & 1,289 &, 000 & 3,630 & 3,108 & 4,239 \\
\hline Initial systolic pressure $<90$ & ,695 &, 000 & 2,004 & 1,804 & 2,227 \\
\hline Systolic pressure $<90$ upon admission & 1,106 &, 000 & 3,023 & 2,706 & 3,377 \\
\hline AIS Head $\geq 3$ & 1,367 &, 000 & 3,922 & 3,552 & 4,332 \\
\hline AIS Abdomen $\geq 3$ & ,314 & ,000 & 1,368 & 1,222 & 1,533 \\
\hline Sternal fracture &,- 228 &, 008 &, 796 &, 672 &, 943 \\
\hline Structural heart injury (AIS $\geq 3$ ) & 1,502 &, 000 & 4,491 & 2,894 & 6,970 \\
\hline Constant & $-3,519$ &, 000 &, 030 & & \\
\hline
\end{tabular}

The variables influencing the target variable mortality following blunt thoracic trauma have been investigated using logistic regression analysis and forward selection for each variable as documented in the registry. 


\begin{tabular}{|c|c|c|c|}
\hline & Non standardized coefficients & Standardized coefficients & Significance $p=$ \\
\hline (constant) & $-1,183$ & & ,000 \\
\hline Age $50-59$ years & 1,368 & ,040 &, 000 \\
\hline Age $60-69$ years & 2,584 & ,066 &, 000 \\
\hline Age $70-79$ years & 3,746 & ,086 &, 000 \\
\hline Age over 80 years & 2,887 &, 047 &, 000 \\
\hline Male patient & 1,327 &, 047 &, 000 \\
\hline AlS Head $\geq 3$ & 5,821 & 234 &, 000 \\
\hline AIS Abdomen $\geq 3$ & 1,912 & ,064 &, 000 \\
\hline AIS Extremity $\geq 3$ & 1,317 & ,052 &, 000 \\
\hline Shock $(R R \leq 90)$ upon resuscitation & 2,027 &, 063 &, 000 \\
\hline Shock (RR $\leq 90)$ upon admission & 3,052 & ,079 &, 000 \\
\hline Blood transfusion (under 10 units) & 4,458 & ,153 &, 000 \\
\hline Blood transfusion (over 10 units) & 5,447 & 093 &, 000 \\
\hline Hemothorax minor (AIS 3) & 1,094 &, 032 &, 000 \\
\hline Hemothorax major (AIS 4) & 2,649 & ,069 &, 000 \\
\hline Flail chest unilateral minor (AIS 3) & 823 & ,016 &, 029 \\
\hline Flail chest unilateral major (AIS 4) &, 813 & 015 & ,036 \\
\hline Flail chest bilateral (AIS 5) & 3,927 & ,062 &, 000 \\
\hline Unilateral minor lung laceration (AIS 3) & 2,525 & ,046 &, 000 \\
\hline Unilateral major or bilateral minor lung laceration (AIS 4) & 4,543 & ,086 &, 000 \\
\hline Bilateral major lung laceration (AIS 5) & 5,658 &, 034 &, 000 \\
\hline Lung contusion unilateral minor (AIS 3) & 1,331 & ,050 &, 000 \\
\hline Lung contusion major (AIS 4) & 3,643 & 072 &, 000 \\
\hline Cardiac laceration (AIS $\geq 4$ ) & 8,814 & 045 &, 000 \\
\hline Pneumothorax severe without tension (AIS 4) & 1,089 & 031 &, 008 \\
\hline Tension pneumothorax (AIS 5) & 3,033 &, 050 &, 000 \\
\hline Major intrathoracic vessel lesion (AIS 5/6) & 6,231 &, 036 &, 000 \\
\hline
\end{tabular}

with an increased risk of mortality and elevated mean duration of ventilation. However, we report on the outcome of a collective of over 10000 patients with different degrees of lung contusion following blunt chest trauma for the first time in the present study.

Previous reports on the impact and outcome of pulmonary laceration following blunt chest trauma are scarce. Two Japanese studies of 13 and 42 cases report mortality rates as high as $44 \%$ following pulmonary lacerations $[24,25]$. However, we detected lung lacerations in $12 \%$ of patients with severe blunt chest trauma making the diagnosis of a lung laceration a very common finding. The high frequency of lung lacerations is most likely mediated by the frequent use of CT scans in recent years. In our study, only bilateral lung laceration was an actually independent risk factor for mortality following blunt chest trauma, while lung lacerations were common. On the other hand, all forms of blunt chest trauma are predictive of longer ventilation.

Previous reports on intrathoracic vessel injuries and cardiac lacerations have already suggested that these are associated with high mortality $[7,26]$. Not surprisingly, we found these the most lethal injuries following blunt chest trauma and as suggested by long ventilation they cause significant morbidity in survivors.

The use of computed tomography (CT) scans in polytrauma patients is emerging in the last years with recent evidence hinting at a benefit in early survival after initial use of CT [13]. The use of CT for the evaluation of patients with blunt chest trauma has been common practice for 15 years and yields more diagnoses than common chest $\mathrm{X}$-rays $[10,11]$. However, the initially treating physician is confronted with an ever-increasing number of possible diagnoses following the first evaluation after blunt chest 
trauma using CT. Treatment decisions such as definite care versus damage control operations depend on the correct evaluation of the individual patient's risk profile [27] and should be accurately based on evidence. The issue has been addressed before, but with less emphasis on the individual injuries encountered in these patients [2]. Based on the analysis of over 20000 patients with blunt chest trauma, our study provides physicians with evidence as to which injuries affect survival and cause prolonged ventilation. Future studies have to be conducted based on the current data to transform this into potential changes of action for clinical practice.

The limitations of the study arise mostly from its methodology. The study is strictly retrospective. Furthermore, diagnoses are only identified by their AIS codes, thus no absolutely strict description of each individual patient's injuries is given. Furthermore, the study leaves out the duration of ventilation in patients who died in the first 14 days following trauma, thus creating a potential bias.

\section{Conclusions}

We demonstrate quantitatively the influence of specific structural damages of the chest on critical outcome parameters. While most injuries of the chest wall have no or only limited impact in the study collective, injuries to the lung overall show adverse outcome. Injuries to the heart or thoracic vessels have a devastating prognosis following blunt chest trauma.

\section{Competing interests}

The authors declare that they have no competing interest.

\section{Authors' contribution}

SH and RL analyzed the data set. SH, MvG and SHW planned the study and subgroups. RL performed statistical analysis. PD, HT, HW and PB contributed to study design and completion of the manuscript. All authors read and approved the final manuscript.

\section{Acknowledgements}

The authors would like to thank Friedrich Seidl for his linguistic advice with this manuscript.

\section{Funding}

The study has been funded entirely by the Technical University of Munich. The Technical University of Munich as an institution has not played a role in design, in the collection, analysis, and interpretation of data; in the writing of the manuscript; and in the decision to submit the manuscript for publication.

\section{Author details}

'Department of Trauma Surgery, Klinikum rechts der Isar, Technical University Munich - TUM, Ismaninger Str. 22, D-81675 Munich, Germany. ${ }^{2}$ IFOM Institute for Research in Operative Medicine, University Witten/Herdecke, Faculty of Health, Ostmerheimer Str. 200, D-51109 Cologne, Germany. ${ }^{3}$ Department of General, Vascular, Transplantation and Thoracic SurgeryGrosshadern Campus, Munich University Hospital (LMU), Marchioninistr. 15, D-81377 Munich, Germany. ${ }^{4}$ Institute for Emergency Medicine and Medical Management, University of Munich, Schillerstr. 53, D-80336 Munich, Germany. ${ }^{5}$ Committee on Emergency Medicine, Intensive Care and Trauma Management (Sektion NIS) of the German Trauma Society (Deutsche Gesellschaft für Unfallchirurgie ,DGU), Munich, Germany.
Received: 28 May 2014 Accepted: 21 August 2014

Published: 3 September 2014

\section{References}

1. Veysi VT, Nikolaou VS, Paliobeis C, Efstathopoulos N, Giannoudis PV: Prevalence of chest trauma, associated injuries and mortality: a level I trauma centre experience. Int Orthop 2009, 33(5):1425-1433.

2. Mommsen P, Zeckey C, Andruszkow $H$, Weidemann J, Fromke C, Puljic $P$, van Griensven M, Frink M, Krettek C, Hildebrand F: Comparison of different thoracic trauma scoring systems in regards to prediction of post-traumatic complications and outcome in blunt chest trauma. J Surg Res 2012, 176(1):239-247.

3. Liman ST, Kuzucu A, Tastepe Al, Ulasan GN, Topcu S: Chest injury due to blunt trauma. Eur J Cardiothorac Surg 2003, 23(3):374-378.

4. Pape HC, Remmers D, Rice J, Ebisch M, Krettek C, Tscherne H: Appraisal of early evaluation of blunt chest trauma: development of a standardized scoring system for initial clinical decision making. J Trauma 2000, 49(3):496-504.

5. Soderlund T, Ikonen A, Pyhältö T, Handolin L: Factors associated with in-hospital outcomes in 594 consecutive patients suffering from severe blunt chest trauma. Scand J Surg 2014, 0:1-6.

6. Clark GC, Schecter WP, Trunkey DD: Variables affecting outcome in blunt chest trauma: flail chest vs. pulmonary contusion. J Trauma 1988, 28(3):298-304.

7. Pretre R, Chilcott M: Blunt trauma to the heart and great vessels. N Engl J Med 1997, 336(9):626-632.

8. de Moya MA, Manolakaki D, Chang Y, Amygdalos I, Gao F, Alam HB, Velmahos GC: Blunt pulmonary contusion: admission computed tomography scan predicts mechanical ventilation. J Trauma 2011, 71(6):1543-1547.

9. Tyburski JG, Collinge JD, Wilson RF, Eachempati SR: Pulmonary contusions: quantifying the lesions on chest $\mathrm{X}$-ray films and the factors affecting prognosis. J Trauma 1999, 46(5):833-838.

10. Trupka A, Waydhas C, Hallfeldt KK, Nast-Kolb D, Pfeifer KJ, Schweiberer L: Value of thoracic computed tomography in the first assessment of severely injured patients with blunt chest trauma: results of a prospective study. J Trauma 1997, 43(3):405-411. discussion 411-2.

11. Traub M, Stevenson M, McEvoy S, Briggs G, Lo SK, Leibman S, Joseph T: The use of chest computed tomography versus chest $\mathrm{X}$-ray in patients with major blunt trauma. Injury 2007, 38(1):43-47.

12. Ruchholtz S: The Trauma Registry of the German Society of Trauma Surgery as a basis for interclinical quality management. A multicenter study of the German Society of Trauma Surgery. Unfallchirurg 2000, 103(1):30-37.

13. Huber-Wagner S, Lefering R, Qvick LM, Korner M, Kay MV, Pfeifer KJ, Reiser M, Mutschler W, Kanz KG: Effect of whole-body CT during trauma resuscitation on survival: a retrospective, multicentre study. Lancet 2009, 373(9673):1455-1461.

14. Battle $C E$, Hutchings $H$, Evans PA: Risk factors that predict mortality in patients with blunt chest wall trauma: a systematic review and meta-analysis. Injuny 2012, 43(1):8-17.

15. Holcomb JB, McMullin NR, Kozar RA, Lygas MH, Moore FA: Morbidity from rib fractures increases after age 45. J Am Coll Surg 2003, 196(4):549-555.

16. Bulger EM, Arneson MA, Mock CN, Jurkovich GJ: Rib fractures in the elderly. J Trauma 2000, 48(6):1040-1046. discussion 1046-7.

17. Livingston DH, Shogan B, John P, Lavery RF: CT diagnosis of Rib fractures and the prediction of acute respiratory failure. J Trauma 2008, 64(4):905-911.

18. Flagel BT, Luchette FA, Reed RL, Esposito TJ, Davis KA, Santaniello JM, Gamelli RL: Half-a-dozen ribs: the breakpoint for mortality. Surgery 2005, 138(4):717-723. discussion 723-5.

19. Whitson BA, McGonigal MD, Anderson CP, Dries DJ: Increasing numbers of rib fractures do not worsen outcome: an analysis of the national trauma data bank. Am Surg 2013, 79(2):140-150.

20. Wright SW: Myth of the dangerous sternal fracture. Ann Emerg Med 1993, 22(10):1589-1592.

21. Celik B, Sahin E, Nadir A, Kaptanoglu M: Sternum fractures and effects of associated injuries. Thorac Cardiovasc Surg 2009, 57(8):468-471.

22. Freedland M, Wilson RF, Bender JS, Levison MA: The management of flail chest injury: factors affecting outcome. J Trauma 1990, 30(12):1460-1468

23. Borman JB, Aharonson-Daniel L, Savitsky B, Peleg K: Unilateral flail chest is seldom a lethal injury. Emerg Med J 2006, 23(12):903-905.

24. Nishiumi N, Inokuchi S, Oiwa K, Masuda R, Iwazaki M, Inoue H: Diagnosis and treatment of deep pulmonary laceration with intrathoracic hemorrhage from blunt trauma. Ann Thorac Surg 2010, 89(1):232-238. 
25. Matsumoto K, Noguchi T, Ishikawa R, Mikami H, Mukai H, Fujisawa T: The surgical treatment of lung lacerations and major bronchial disruptions caused by blunt thoracic trauma. Surg Today 1998, 28(2):162-166.

26. Nan YY, Lu MS, Liu KS, Huang YK, Tsai FC, Chu JJ, Lin PJ: Blunt traumatic cardiac rupture: therapeutic options and outcomes. Injury 2009, 40(9):938-945

27. Tuttle MS, Smith WR, Williams AE, Agudelo JF, Hartshorn CJ, Moore EE, Morgan SJ: Safety and efficacy of damage control external fixation versus early definitive stabilization for femoral shaft fractures in the multiple-injured patient. J Trauma 2009, 67(3):602-605.

doi:10.1186/s13049-014-0052-4

Cite this article as: Huber et al:: Predictors of poor outcomes after significant chest trauma in multiply injured patients: a retrospective analysis from the German Trauma Registry (Trauma Register DGU). Scandinavian Journal of Trauma, Resuscitation and Emergency Medicine $201422: 52$

\section{Submit your next manuscript to BioMed Central and take full advantage of:}

- Convenient online submission

- Thorough peer review

- No space constraints or color figure charges

- Immediate publication on acceptance

- Inclusion in PubMed, CAS, Scopus and Google Scholar

- Research which is freely available for redistribution 